\title{
Métodos simples para determinação do perímetro e área de terrenos com pequenas dimensões
}

\author{
Pedro Adenilson Silva de Lima ${ }^{1}$, Alexandre José Soares Minál, Jacob Soares Pereira Neto ${ }^{2}$, \\ Maria José AraújoWanderley ${ }^{1}$
}

${ }^{1}$ Universidade Federal da Paraíba; pedro.adenilson@hotmail.com; alexminah.ufpb@gmail.com; mjwander@gmail.com; ${ }^{2}$ Geosuperfície; jacob_spn@yahoo.com.br.

RESUMO: Além de suas bases científicas, a agroecologia incorpora conhecimentos empíricos, acumulados pelos próprios agricultores, na busca por padrões de produção mais sustentáveis. Na agricultura familiar, em geral, o manejo do solo e das plantas é realizado de maneira pouco agressiva e é comum o uso de métodos tradicionais e de baixo custo, práticas próximas dos valores defendidos pela agroecologia. A maioria dos trabalhos topográficos relacionados com a agricultura familiar é de natureza simples e podem ser realizados pelos próprios agricultores. O objetivo deste trabalho foi comparar os resultados obtidos para a determinação do perímetro e área, de um terreno com pequenas dimensões, através da aplicação de dois métodos distintos: método da triangulação, com o auxílio de uma trena e o método do caminhamento, com o uso de um "smartphone" e um aplicativo GPS. As diferenças entre os valores médios, obtidos com o aplicativo, e os respectivos valores obtidos com a trena foram de 3,35 m $(1,1 \%)$ para o perímetro e de $81,23 \mathrm{~m}^{2}$ $(1,5 \%)$ para área. Quando necessário maior precisão, na determinação do perímetro e área de pequenas propriedades rurais, recomenda-se o uso da trena. O aplicativo pode ser usado como ferramenta de planejamento, na obtenção de dados preliminares.

PALAVRAS-CHAVE: Topografia; Agricultura familiar; "Smartphone”.

\section{INTRODUÇÃO}

Agroecologia pode ser entendida como a ciência que estabelece base e estratégias para a construção da atividade agrícola mais justa e sustentável. De modo paralelo, a agroecologia busca incorporar conhecimentos e saberes acumulados pelos próprios agricultores, na implementação de um método de intervenção, que mantenha a coerência com suas bases científicas, e ao mesmo tempo contribua na formação de padrões de produção e consumo mais sustentáveis (CAPORAL e COSTABEBER, 2004).

A agricultura na sua forma mais simples e tradicional sempre foi garantia de subsistência para muitas famílias rurais. Na agricultura familiar, geralmente, o manejo do solo e das plantas é realizado de maneira pouco agressiva, contínua, e de acordo com as exigências do ambiente e das culturas trabalhadas. Além disso, na agricultura familiar é comum a aplicação do conhecimento empírico, dos métodos tradicionais, e do baixo uso de insumos externos (NASCIMENTO e COSTA CRUZ, 2014).

A agricultura familiar tem dinâmica e aspectos próprios. Tem como características fundamentais a gestão da propriedade compartilhada pela família, a diversidade produtiva, e a atividade agropecuária como principal fonte de renda. O agricultor familiar tem uma relação particular com a terra, seu local de trabalho e moradia. Segundo dados do Censo Agropecuário de 2006, 84,4\% dos estabelecimentos agropecuários brasileiros pertencem a grupos familiares. São aproximadamente 4,4 milhões de estabelecimentos, com metade deles na Região Nordeste (MAPA, 2019).

Em qualquer tipo de atividade agropecuária, o conhecimento sobre o perímetro e área do local contribui com informações básicas e essenciais que auxiliam no planejamento e controle da produção. A maioria dos trabalhos topográficos relacionados com a agricultura familiar é de natureza simples (medições de pequenas áreas, por exemplo) e podem ser realizados pelos próprios agricultores, sem a necessidade de métodos e equipamentos sofisticados.

A sigla GNSS significa "Sistema Global de Navegação por Satélite" e é usada em referência a sistemas capazes de localizar objetos na superfície terrestre, por meio de aparelhos que recebem ondas de rádio emitidas por satélites. Entre esses sistemas globais podem ser citados: GLONASS (Rússia), GALILEO (União Europeia), COMPASS (China) e GPS (EUA) o mais popular dos sistemas de navegação por satélite. Receptor GPS é um equipamento que consegue captar as ondas de rádio do sistema GPS e calcular suas respectivas coordenadas geodésicas (latitude, longitude e altitude). Existem diversos tipos de receptores GPS, variando desde os de Navegação (baixa precisão) até os Geodésicos, de alta precisão.

É inquestionável a popularização dos telefones celulares inteligentes ("smartphones") que incorporam diversos dispositivos, tais como: acelerômetros, câmeras, armazenamento de dados em cartão SD e receptores GPS de navegação (LIMA, 2018). Através do uso de um receptor GPS, embutido no celular, e do uso de um aplicativo (programa de computador específico) é possível obter a localização do aparelho, e consequentemente, determinar o perímetro e a área de regiões da superfície terrestre, de forma simples e rápida, após serem localizados os vértices da referida superfície. A facilidade na obtenção dessas informações, nem sempre é acompanhada do conhecimento sobre a precisão dos dados 
LIMA, P. A. S. et al. Métodos simples para determinação do perímetro e área de terrenos com pequenas dimensões. In: II Congresso Paraibano de Agroecologia \& IV Exposição Tecnológica, 2019. Anais... Caderno Verde de Agroecologia e Desenvolvimento

Sustentável, Pombal, v. 9, n.7, e-6915, 2019.

coletados. Muitas vezes a sofisticação do método de obtenção das informações (uso de satélites, "software", etc.) transmite a falsa impressão de "alta precisão" aos resultados obtidos.

Existem métodos simples e de baixo custo que possibilitam a determinação do perímetro e da área de pequenas porções da superfície terrestre, como o método antigo e tradicional da topografia que usa apenas um diastímetro (trena) e alguns acessórios (balizas), que aqui será denominado de triangulação com trena. Outro método, que pode ser aplicado com a mesma finalidade, usa apenas um aparelho celular e um aplicativo gratuito, e será aqui denominado de caminhamento com aplicativo. Assim, é possível se utilizar essas ferramentas como subsídio na medição de pequenas áreas, a exemplo de propriedades familiares rurais.

Diante desse contexto este trabalho teve como objetivo comparar o método da triangulação com trena e o método do caminhamento com aplicativo, na obtenção do perímetro e área de um terreno com pequena dimensão.

\section{MATERIAL E MÉTODOS}

Área de estudo: O trabalho foi desenvolvido em um terreno, relativamente plano, localizado no setor de bovinocultura (Figura 1) do Centro de Ciências Humanas, Sociais e Agrárias (CCHSA) da Universidade Federal da Paraíba (UFPB), na cidade de Bananeiras - PB, que fica a $141 \mathrm{~km}$ da capital do estado.

Figura 1 - Vista superior do terreno, com os vértices (A, B, C, D) destacados. Bananeiras-PB. 2019.

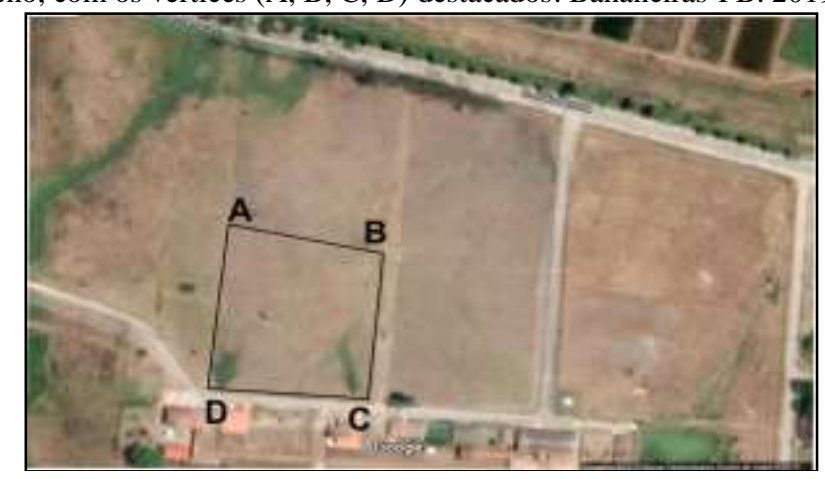

Inicialmente, dentro de uma área de pastagem do setor de bovinocultura, foram fixados quatro piquetes de madeira, formando um quadrilátero, aproximadamente retangular, de modo que se pudesse percorrer, facilmente, as distâncias entre os piquetes. Os vértices do terreno foram identificados com as letras A, B, C e D, começando pelo vértice superior esquerdo e continuando no sentido horário, conforme ilustrado na Figura 1.

Triangulação com Trena - A decomposição em triângulos, ou triangulação, é uma estratégia muito usada em levantamento de pequenas áreas. Consiste em decompor a área em triângulos justapostos e medir os lados dos triângulos. A área total do terreno será a soma das áreas parciais (área dos triângulos) em que a mesma foi subdividida.

O terreno estudado tem a forma de um quadrilátero, e, portanto, tem duas diagonais (AC e BD, na Figura 1). Assim, é possível dividir o terreno em dois triângulos, por intermédio de uma dessas diagonais. Para cálculo da área (A) dos triângulos foi usada a fórmula de Héron: $\mathbf{A}=[\mathbf{S}(\mathbf{S}-\mathbf{a})(\mathbf{S}-\mathbf{b})(\mathbf{S}-\mathbf{c})]^{1 / 2}$, em que: $\mathrm{S}=$ semiperímetro e a, b, c = lados do triângulo.

Nas medições com a trena, de 50 metros de comprimento máximo, o seguinte procedimento foi repetido por 10 vezes. Mediram-se, em sequência, os quatro lados e as duas diagonais do terreno, e cada medição de distância foi realizada duas vezes, ida e volta, ou seja, em um sentido e depois no sentido contrário. Portanto, cada dimensão (lado ou diagonal) foi medida 20 vezes. Os valores médios dessas medições foram usados para cálculo do perímetro e área do terreno. Esses valores foram considerados os valores reais do terreno e foram usados como referência, para comparação com os valores determinados através do método de caminhamento.

Caminhamento com Aplicativo - Foi usado um "smartphone", da marca LG (modelo K8) no qual se instalou o aplicativo C7 GPS DADOS, obtido gratuitamente na plataforma "Google Play Store”, que é a loja virtual oficial de aplicativos (e outras mídias digitais, como músicas, filmes, etc.) para smartphones e tablets que usam o sistema operacional Android. O aplicativo foi desenvolvido pela Universidade Federal de Santa Maria (UFSM) e pode ser usado para obtenção das coordenadas de pontos isolados, como os vértices de uma poligonal fechada, por exemplo.

A partir das coordenadas dos vértices de um terreno, o aplicativo determina imediatamente os respectivos valores do perímetro e área. O aplicativo possui quatro páginas principais: Pontos (que permite a obtenção e armazenamento das coordenadas de pontos isolados); Trajeto (que é usada para determinação da velocidade do percurso e obtenção de pontos em intervalos de tempo regulares); Satélites (que permite a visualização da constelação de satélites e as intensidades dos sinais) e Cálculos (que é usada para determinação da área e perímetro de uma poligonal fechada). 
LIMA, P. A. S. et al. Métodos simples para determinação do perímetro e área de terrenos com pequenas dimensões. In: II Congresso Paraibano de Agroecologia \& IV Exposição Tecnológica, 2019. Anais... Caderno Verde de Agroecologia e Desenvolvimento

Sustentável, Pombal, v. 9, n.7, e-6915, 2019.

Nas medições com o aplicativo foi usado o seguinte procedimento: Posicionava-se o aparelho celular a uma altura aproximada de $1,30 \mathrm{~m}$ sobre o vértice inicial, com a página "Pontos" selecionada, e permanecia-se nessa posição por, aproximadamente, 1 minuto, buscando-se estabilizar os níveis dos sinais dos satélites, e consequentemente, melhorar a precisão na localização do ponto. Em seguida identificava-se o vértice (digitava-se, P1) e "salvava-se" a localização. Caminhava-se, no sentido horário, até o próximo vértice e repetia-se o procedimento descrito. Assim, foram identificados os vértices P1, P2, P3 e P4, que correspondem aos quatro vértices do terreno. Após salvar o vértice P4 retornava-se até o vértice inicial e salvava-se um "quinto" vértice, sobrepondo o inicial. Portanto, o vértice inicial e o final teriam as mesmas coordenadas. A realização dessa última etapa é necessária para se "fechar" a poligonal medida, e, consequentemente, serem realizadas as determinações do perímetro e área do terreno. Para essas determinações bastava selecionar a página "cálculos" (Figura 2).

Figura 2 - Página "Cálculos” do C7 GPS DADOS, indicando valores do perímetro e área do terreno estudado. Bananeiras-PB. 2019.

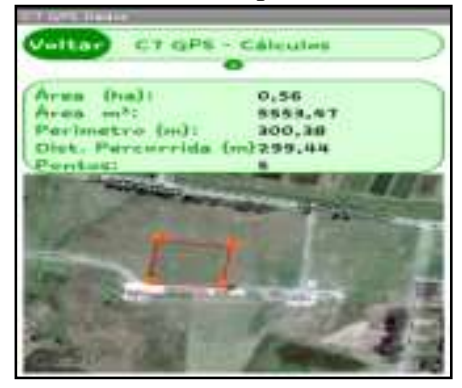

\section{RESULTADOS E DISCUSSÃO}

Na Tabela 1 podem ser vistos os valores médios e o desvio padrão das medições dos lados e das diagonais, do terreno estudado.

Tabela 1. Média e desvio padrão de 20 medições realizadas com trena em uma área de pastagem. Bananeiras- PB. 2019.

\begin{tabular}{|c|c|c|c|c|c|c|}
\hline \multirow{2}{*}{$\begin{array}{c}\text { Média e } \\
\text { Desvio Padrão }\end{array}$} & \multicolumn{4}{|c|}{ LADOS (m) } & \multicolumn{2}{|c|}{ DIAGONAIS } \\
\hline & $\mathrm{AB}$ & $\mathrm{BC}$ & $\mathrm{CD}$ & DA & $\mathrm{AC}$ & $\mathrm{BD}$ \\
\hline MÉDIA & 73,45 & 72,55 & 72,73 & 78,89 & 106,05 & 103.83 \\
\hline D. PADR ÃO & 0,05 & 0,09 & 0,18 & 0,08 & 0,11 & 0,07 \\
\hline
\end{tabular}

Todos os resultados de desvio padrão ficaram abaixo de $20 \mathrm{~cm}$, indicando baixa variabilidade e, portanto, boa precisão nas medições dos quatro lados e das duas diagonais do terreno. A partir dos valores médios dos lados calculouse o perímetro real do terreno, ou seja, somando-se os valores médios de AB, BC, CD e DA.

A partir dos valores médios dos lados, e do valor médio da diagonal BD (escolhida por apresentar menor desvio padrão que a diagonal AC) foi calculada a área real do terreno. Para isso foi usado o procedimento de decomposição do terreno em triângulos, conforme explicado anteriormente. Na Tabela 2 pode ser observado o valor do perímetro real do terreno, além dos valores das áreas parciais (triângulos) e da área total $\left(\mathrm{A}_{\mathrm{TOTAL}}=\right.$ soma das áreas dos dois triângulos) considerada como a área real do terreno.

Tabela 2. Valor real do perímetro; Valores das áreas parciais (triângulos) e da área total, considerada como a área real do terreno estudado, obtidos a partir do método de triangulação com trena. Bananeiras-PB. 2019.

\begin{tabular}{c|c|c}
\hline \multicolumn{3}{c}{ PERÍMETRO REAL $=\mathrm{AB}+\mathrm{BC}+\mathrm{CD}+\mathrm{DA}=297,61 \mathrm{~m}$} \\
\hline \multicolumn{3}{c}{ ÁREAS $\left(\mathrm{m}^{2}\right)$} \\
\hline$*_{\mathrm{BDA}}$ & $\mathrm{A}_{\mathrm{BDC}}$ & ÁREA REAL $=\mathrm{A}_{\mathrm{TOTAL}}=\mathrm{A}_{\mathrm{BDA}}+\mathrm{A}_{\mathrm{BDC}}$ \\
\hline 2895,43 & 2632,47 & 5527,90 \\
\hline
\end{tabular}

*A $\mathrm{A}_{\mathrm{BDA}}=$ Área do triângulo, cujos vértices são os pontos B, D e A (idem para A $\mathrm{BDC}$ )

Na Tabela 3 podem ser vistos os valores médios e o desvio padrão das 30 determinações do perímetro e área, do terreno estudado, realizadas por caminhamento, com celular e aplicativo.

Tabela 3. Média e desvio padrão de 30 determinações, realizadas com celular e aplicativo, em área de pastagem. Bananeiras-PB, 2019.

\begin{tabular}{c|c|c}
\hline Média e Desvio Padrão & PERÍMETRO $(\mathrm{m})$ & ÁREA $\left(\mathrm{m}^{2}\right)$ \\
\hline MÉDIA & 300,96 & 5609,13 \\
\hline DESVIO PADRÃO & 1,34 & 66,44 \\
\hline
\end{tabular}


As diferenças entre os valores médios (obtidos com o aplicativo) e os respectivos valores de referência (obtidos com a trena) foram de 3,35 m (1,1\%) para o perímetro, e de 81,23 $\mathrm{m}^{2}(1,5 \%)$ para área. Percentualmente são valores baixos, mas não são valores desprezíveis, em termos absolutos. Para melhor avaliação, os resultados obtidos com os dois métodos foram testados, estatisticamente, por meio do teste $\mathrm{T}$ para uma amostra, bi-caudal, com nível de significância $\left(\right.$ alfa) $=1 \%$ (MAGALHÃES e PEDROSO DE LIMA, 2002). Adotou-se como Hipótese $\left(\mathrm{H}_{0}\right)$ : “A média das medições obtidas com o aplicativo é estatisticamente equivalente ao valor de referência, obtido com a trena".

O teste estatístico, aplicado aos dados de perímetro, apresentou o seguinte resultado: $\mathrm{T}$ calculado $=13,69>\mathrm{T}$ crítico $=2,76$. Da mesma forma, quando o teste estatístico foi aplicado aos dados de área, o resultado foi o seguinte: $\mathrm{T}$ calculado $=6,69>\mathrm{T}$ crítico $=2,76$. Como o valor do $\mathrm{T}$ calculado foi superior ao valor de $\mathrm{T}$ crítico, tanto para os dados de perímetro, como para os dados de área, então a hipótese $\mathrm{H}_{0}$ foi rejeitada em ambos os casos. Assim, pode-se afirmar que o perímetro médio e a área média, obtidos com o auxílio do aparelho celular e do aplicativo, são estatisticamente diferentes dos respectivos valores de referência (valores reais) determinados com o auxílio da trena.

Melo et al. (2011) chegaram a resultados semelhantes ao comparar o perímetro e a área de 12 terrenos (com áreas aproximadas de $10.000 \mathrm{~m}^{2}$ ) obtidos de duas formas diferentes: receptor GPS de navegação versus teodolito eletrônico (aparelho de uso comum em topografia) concluindo que os resultados obtidos com os dois aparelhos são, estatisticamente, diferentes. Ou seja, para terrenos com dimensões semelhantes aos estudados, quando necessário maior precisão na determinação do perímetro e área, é melhor usar o teodolito.

Rodrigues (1979) afirmou que a ciência vinha modificando a técnica topográfica, tornando obsoletos muitos processos e instrumentos. Mas, frequentemente, novos equipamentos e processos substituíam os antigos apenas em trabalhos grandes e complicados. Nos menores e mais simples, os métodos e instrumentos do passado permaneciam. Os resultados obtidos neste trabalho parecem confirmar essa afirmação. Portanto, em áreas com pequenas dimensões (por volta de $5000 \mathrm{~m}^{2}$ ) como é frequente na agricultura familiar, é preferível usar o método tradicional de triangulação com trena, nas determinações dos respectivos valores do perímetro e área. Recomenda-se cautela no uso do método do caminhamento, com auxílio de aparelhos celulares e aplicativos. Os valores obtidos por meio desse último método devem ser entendidos, apenas, como estimativas de base para obtenção dos respectivos valores reais.

\section{CONCLUSÕES}

Comparando-se os dois métodos, utilizados para determinação do perímetro e área de um terreno com pequenas dimensões, foi constatado que o método da triangulação com trena é o mais indicado, tendo em vista ser mais preciso. Já o método do caminhamento com aplicativo pode ser usado, desde que suas informações sejam entendidas, apenas, como estimativas iniciais dos valores reais do perímetro e área de terrenos com pequenas dimensões.

\section{REFERÊNCIAS}

CAPORAL, F.R.; COSTABEBER, J.A. Agroecologia: alguns conceitos e princípios. Brasília: MDA/SAF/DATERIICA, 2004. 24p.

LIMA,E.C. Proposta de metodologia para melhora do posicionamento obtido através de receptores GPS de baixo custo. 2018. 197p. Tese (Doutorado) - Escola Politécnica da Universidade de São Paulo. Departamento de Engenharia de Transportes, São Paulo, 2018.

MAGAlHÃES, M.N.; PEDROSO DE LIMA, A.C. Noções de Probabilidade e Estatística. São Paulo: EDUSP, 2002, 392p.

MAPA. Ministério da Agricultura, Pecuária e Abastecimento. O que é a agricultura familiar. Secretaria de Agricultura Familiar e Cooperativismo. Disponível, em: < http://www.mda.gov.br/sitemda/noticias/o-que-\%C3\%A9agricultura-familiar >. Acesso em: 12/08/2019.

MELO, A.S.; MINÁ,A.J.S.; AQUINO, I.S.; OLIVEIRA, A.G.; ASSIS, V.H.S. O uso do GPS de navegação em pequenas áreas agrícolas. Revista Verde, Mossoró, v.6, n.4, p.137 - 141, 2011.

NASCIMENTO, A.S.; COSTA CRUZ, S.M. Agroecologia. São Luís: IFMA, 2014, 69p.

RODRIGUES, J. C. Topografia. Rio de Janeiro: Livros Técnicos e Científicos Editora, 1979, 115p.

\section{AGRADECIMENTOS}

Apoio financeiro: Fundação de Apoio à Pesquisa do Estado da Paraíba - FAPESQ. 